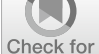

Check for

updates

Cite as

Nano-Micro Lett.

(2021) 13:167

Received: 28 April 2021

Accepted: 12 July 2021

Published online: 5 August 2021

(C) The Author(s) 2021

\section{Oxygen-Defect Enhanced Anion Adsorption Energy Toward Super-Rate and Durable Cathode for Ni-Zn Batteries}

\author{
Jia Yao ${ }^{1}$, Houzhao Wan ${ }^{1} \bowtie$, Chi Chen ${ }^{2,3}{ }^{凶}, \mathrm{Jie} \mathrm{Ji}^{1}{ }^{1}$, Nengze Wang ${ }^{1}$, Zhaohan Zheng ${ }^{1}$, \\ Jinxia Duan ${ }^{1}$, Xunying Wang ${ }^{1}$, Guokun $\mathrm{Ma}^{1}, \mathrm{Li} \mathrm{Tao}^{1}$, Hanbin Wang ${ }^{1}$, Jun Zhang ${ }^{1}$, \\ Hao Wang ${ }^{1 凶}$
}

\title{
HIGHLIGHTS
}

- Ultra-thin $\mathrm{CoNiO}_{2}$ nanosheet with rich oxygen defects anchored on the vertically arranged Ni nanotube arrays $\left(\mathrm{O}_{\mathrm{d}}-\mathrm{CNO} @ \mathrm{Ni} \mathrm{NTs}\right)$ is successfully constructed.

- The $\mathrm{O}_{\mathrm{d}}-\mathrm{CNO} @ \mathrm{Ni}$ NTs electrode delivers extraordinary electrochemical performance.

- The theoretical calculations reveal that oxygen defects effectively improve the electrochemical kinetics and the surface electronic state structure of $\mathrm{O}_{\mathrm{d}} \mathrm{CNO} @ \mathrm{Ni} \mathrm{NTs}$, thus exhibiting strong $\mathrm{OH}^{-}$adsorption capacity.

\begin{abstract}
The alkaline zinc-based batteries with high energy density are becoming a research hotspot. However, the poor cycle stability and low-rate performance limit their wide application. Herein, ultra-thin $\mathrm{CoNiO}_{2}$ nanosheet with rich oxygen defects anchored on the vertically arranged Ni nanotube arrays $\left(\mathrm{O}_{\mathrm{d}}-\mathrm{CNO} @ \mathrm{Ni} \mathrm{NTs}\right)$ is used as a positive material for rechargeable alkaline $\mathrm{Ni}-\mathrm{Zn}$ batteries. As the highly uniform $\mathrm{Ni}$ nanotube arrays provide a fast electron/ion transport path and abundant active sites, the $\mathrm{O}_{\mathrm{d}}$-CNO@Ni NTs electrode delivers excellent capacity $\left(432.7 \mathrm{mAh} \mathrm{g}^{-1}\right)$ and rate capability (218.3 $\mathrm{mAh} \mathrm{g}^{-1}$ at $60 \mathrm{~A} \mathrm{~g}^{-1}$ ). Moreover, our $\mathrm{O}_{\mathrm{d}^{-}} \mathrm{CNO} @ \mathrm{Ni} \mathrm{NTs} / / \mathrm{Zn}$ battery is capable of
\end{abstract}

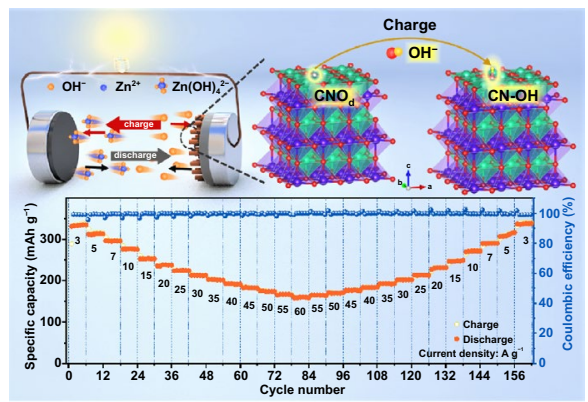
an ultra-long lifespan ( $93.0 \%$ of initial capacity after 5000 cycles), extremely high energy density of $547.5 \mathrm{Wh} \mathrm{kg}^{-1}$ and power density of $92.9 \mathrm{~kW} \mathrm{~kg}^{-1}$ (based on the mass of cathode active substance). Meanwhile, the theoretical calculations reveal that the oxygen defects can enhance the interaction between electrode surface and electrolyte ions, contributing to higher capacity. This work opens a reasonable idea for the development of ultra-durable, ultra-fast, and high-energy Ni-Zn battery.

KEYWORDS Ni-Zn battery; Oxygen defect; Nanotube array; $\mathrm{CoNiO}_{2}$ nanosheet; Adsorption energy

Houzhao Wan, houzhaow@ hubu.edu.cn; Chi Chen, xmchenchi@fjirsm.ac.cn; Hao Wang, wangh@hubu.edu.cn; nanoguy@126.com

1 Hubei Key Laboratory of Ferro and Piezoelectric Materials and Devices, School of Microelectronics and Faculty of Physics and Electronic Science, Hubei University, Wuhan 430062, People's Republic of China

2 CAS Key Laboratory of Design and Assembly of Functional Nanostructures, and Fujian Provincial Key Laboratory of Nanomaterials, Fujian Institute of Research on the Structure of Matter, Chinese Academy of Sciences, Fuzhou 350002, People's Republic of China

3 Xiamen Key Laboratory of Rare Earth Photoelectric Functional Materials, Xiamen Institute of Rare Earth Materials, Haixi Institute, Chinese Academy of Sciences, Xiamen 361021, People's Republic of China 


\section{Introduction}

With the increasing demand for green and sustainable energy storage, advanced energy storage technology like lithiumion batteries (LIBs) has attracted extensive attentions [1-3]. However, their applications are seriously hindered caused by the Li dendrite formation and the side reactions, which could cause serious degradation and safety problems [4-6]. As an alternative to LIBs, rechargeable alkaline $\mathrm{Zn}$-based batteries (ZBBs) have attracted more and more attentions with high theoretical capacity $\left(820 \mathrm{mAh} \mathrm{g}^{-1}\right)$, low cost, high security, and good ionic conductivity $[7,8]$.

To date, various alkaline $\mathrm{Zn}$-based cathodes have been developed, such as $\mathrm{MnO}_{2}$ [9], Ag-based [10], and Ni, Cobased materials (e.g., $\mathrm{Ni}(\mathrm{OH})_{2}$ [11, 12], $\mathrm{NiO}$ [13], $\mathrm{NiSe}_{2}$ [14], $\mathrm{Ni}_{3} \mathrm{~S}_{2}[15,16], \mathrm{Co}_{3} \mathrm{O}_{4}$ [17-19], $\mathrm{Co}_{3} \mathrm{~S}_{4}$ [20], NiCo-DH $[21,22]$, and $\left.\mathrm{NiCo}_{2} \mathrm{O}_{4}[23-25]\right)$. While $\mathrm{MnO}_{2}-\mathrm{Zn}$ battery has a low working voltage and weak stability, $\mathrm{AgO}-\mathrm{Zn}$ battery has low stability, poor overcharge tolerance and high cost. Conversely, Ni-Zn batteries (NZBs) have the advantages of high energy density and high output voltage, reversible oxidation-reduction kinetics of $\mathrm{Zn} / \mathrm{ZnO}$, low cost and low toxicity, etc. [26]. However, currently reported cathode materials have low cycle stability due to the self-dissolution of the cathode, the corrosion and dendrite formation of the anode, etc. [27]. Thus, the further development of NZBs is severely restricted.

To address the above limitations, many strategies, including structural design, metal ions doping and surface properties optimization, have been attempted (summarized in Table S1) [28, 29]. Structural design is used to strengthen the electrochemical performance of electrode materials. For example, Chao et al. reported that the NiS@ $\mathrm{Ni}_{0.95} \mathrm{Zn}_{0.05}(\mathrm{OH})_{2}$ used in NZBs has a long life and fast energy response $\left(18.82 \mathrm{~kW} \mathrm{~kg}^{-1}\right.$, peak power output of $30 \mathrm{~s}$ ) [30]. Ionic doping could promote the transmission of ions/electrons and show more redox reactions, thereby contributing to electrochemical performance [31]. Surface modification with the introduction of defects and higher conductivity additives, the surface reactivity and reaction kinetics of electrode materials are improved [32]. Lu et al. reported a mesoporous nanostructured $\mathrm{Co}_{3} \mathrm{O}_{4}$ with oxygen defects as the cathode of ZBBs, providing an excellent long-life performance (the capacity does not decrease after 60,000 cycles) [19]. However, the energy density and cycle lifespan of the NZBs are still far from up to standard for practical applications due to the poor conductivity, limited exposure to active sites, and large volume variations for cathode materials. In summary, the exploration of cathode materials with ultra-high capacity, high rate capability and long life is still full of challenges and desirability.

Nickel cobaltate has superior electrochemical activity than oxides of single metal nickel or cobalt due to the electronic transition between the different valence states of the elements and the existence of $\mathrm{Co}^{3+} / \mathrm{Co}^{2+}$ and $\mathrm{Ni}^{3+} / \mathrm{Ni}^{2+}$ redox pairs [33]. Shang et al. prepared porous $\mathrm{NiCo}_{2} \mathrm{O}_{4}$ nanosheets, nanowires and nanoplates as cathode of NZBs, which promoted electron transfer and electrochemical reaction, thereby showing excellent electrochemical performance [24]. However, the volume expansion of $\mathrm{CoNiO}_{2}$ $(\mathrm{CNO})$ cathode during the charge-discharge, resulting in poor connection of the electron transmission channel and greatly reduced electrical conductivity, thus making its capacity and high-rate performance far from expected. Herein, we develop an unprecedented composite material that combines electrochemically active structures and defect engineering. Ultra-thin $\mathrm{CoNiO}_{2}$ nanosheets with abundant oxygen defects $\left(\mathrm{O}_{\mathrm{d}}-\mathrm{CNO}\right)$ are introduced in situ on the surface of vertically arranged $\mathrm{Ni}$ nanotube arrays (Ni NTs). The density functional theory (DFT) reveals that the introduction of oxygen defects can enhance the adsorption energy of $\mathrm{OH}^{-}$, thereby improving the cycle stability of the crystal structure during charge-discharge. Simultaneously, the oxygen defects can effectively modulate the surface electronic structure to promote charge storage. As a consequence, the $\mathrm{O}_{\mathrm{d}}-\mathrm{CNO} @ \mathrm{Ni}$ NTs electrode shows excellent rate performance and high specific capacity. Concretely, the assembled $\mathrm{O}_{\mathrm{d}}-\mathrm{CNO} @ \mathrm{Ni} \mathrm{NTs} / / \mathrm{Zn}$ rechargeable battery provides a capacity of $334.9 \mathrm{mAh} \mathrm{g}^{-1}$ and has long cycle life (93.0\% retention after 5000 times). In addition, the $\mathrm{Ni}-\mathrm{Zn}$ battery achieves an energy density of $547.5 \mathrm{Wh} \mathrm{kg}^{-1}$ and power density of $92.9 \mathrm{~kW} \mathrm{~kg}^{-1}$. Encouragingly, even after the brutal treatment of hammer and fire, it still shows excellent reliability and safety. This study shows that $\mathrm{O}_{\mathrm{d}^{-}} \mathrm{CNO} @ \mathrm{Ni} \mathrm{NTs} / / \mathrm{Zn}$ has high practical application potential in high-performance ZBBs. 


\section{Experimental}

\subsection{Material Synthesis}

\subsubsection{Fabrication of Ni NTs@Ni Foam}

To obtain regular Ni NTs, the Ni NTs@ZnO array must be synthesized. First, $\mathrm{Zn}\left(\mathrm{CH}_{3} \mathrm{COO}\right)_{2} \cdot 2 \mathrm{H}_{2} \mathrm{O}$ was dissolved in $100 \mathrm{~mL}$ anhydrous methanol $\left(\mathrm{CH}_{3} \mathrm{OH}\right)$, and nickel foam was placed in the solution and stirred by ultrasound, and then stored at $200{ }^{\circ} \mathrm{C}$ for $2 \mathrm{~h}$. Secondly, $0.1 \mathrm{M} \mathrm{Zn}\left(\mathrm{NO}_{3}\right)_{2} \cdot 6 \mathrm{H}_{2} \mathrm{O}$, $0.1 \mathrm{M}$ HMTA $\left(\mathrm{C}_{6} \mathrm{H}_{12} \mathrm{~N}_{4}\right), 0.1 \mathrm{M}$ ammonia and nickel foam were transferred to a $100 \mathrm{~mL}$ Teflon-lined stainless steel, heated at $90{ }^{\circ} \mathrm{C}$ for $10 \mathrm{~h}$. Then, Ni films were electrodeposited on $\mathrm{ZnO}$ nanorods arrays in $0.2 \mathrm{M} \mathrm{NiSO}_{4} \cdot 6 \mathrm{H}_{2} \mathrm{O}$ and $0.01 \mathrm{M} \mathrm{NH}_{4} \mathrm{Cl}$ solutions at $-1.5 \mathrm{~mA} \mathrm{~cm}^{-2}$ for $12 \mathrm{~min}$. After a further immersion in $0.01 \mathrm{M} \mathrm{HCl}$ solution for 5-10 min, the prepared sample is cleaned repeatedly with deionized water and dried.

\subsubsection{Fabrication of $O_{d^{-}} \mathrm{CNO} @ \mathrm{Ni} \mathrm{NTs}, \mathrm{O}_{d^{-}} \mathrm{CNO}$ and $\mathrm{CNO}$}

According to our previous report, a cobalt-based organic skeleton (Co-MOF@Ni NTs) supported on Ni NTs was prepared [31]. In a typical experiment, $4 \mathrm{M}$ 2-methylimidazole $\left(\mathrm{C}_{4} \mathrm{H}_{6} \mathrm{~N}_{2}\right)$ solution was quickly added to $0.05 \mathrm{M}$ $\mathrm{Co}\left(\mathrm{NO}_{3}\right)_{2} \cdot 6 \mathrm{H}_{2} \mathrm{O}$ solution, and then the prepared Ni nanotube arrays (Ni NTs) were infiltrated and grown for $4 \mathrm{~h}$. The prepared Co-MOF@Ni NTs were immersed in $16 \mathrm{mM} \mathrm{NiSO} \cdot \cdot 6 \mathrm{H}_{2} \mathrm{O}$ solution, react at room temperature for $90 \mathrm{~min}$, wash and dry to obtain NiCo-DH@Ni NTs. To obtain $\mathrm{O}_{\mathrm{d}}$-CNO@Ni NTs, the prepared sample was heated to $350{ }^{\circ} \mathrm{C}$ in the Ar environment for $2 \mathrm{~h}$ (heating rate of $\left.2{ }^{\circ} \mathrm{C} \mathrm{min}^{-1}\right)$. In the absence of Ni NTs, the NiCo-DH sample was heated to $350^{\circ} \mathrm{C}$ in $\mathrm{Ar}$ atmosphere for $2 \mathrm{~h}$ (heating rate of $2{ }^{\circ} \mathrm{C} \mathrm{min}^{-1}$ ) to obtain the $\mathrm{O}_{\mathrm{d}}$ - $\mathrm{CNO}$ sample. Similarly, the NiCo-DH sample was heated in air to $350{ }^{\circ} \mathrm{C}$ and held for $2 \mathrm{~h}$ (heating rate of $2{ }^{\circ} \mathrm{C} \mathrm{min}^{-1}$ ) to obtain CNO. The sample loading capacity is about $0.8-1.2 \mathrm{mg} \mathrm{cm}^{-2}$.

\subsection{Material Characterization}

The morphology and size were studied by scanning electron microscopy (SEM, JEOL JSM-7100F), transmission electron microscopy (TEM), high-resolution TEM (HRTEM) and selected area electron diffraction (SAED). Elemental analysis and morphology measurements were obtained by energy-dispersive X-ray spectrometer (EDX). The structure and chemical composition were characterized by X-ray diffraction (XRD; Bruker D8 Advance diffractometer), X-ray photoelectron spectrometer (XPS; Thermo Fisher Scientific Escalab 250Xi) and electron paramagnetic resonance (EPR; Bruker EMPplus-10/12). The $\mathrm{N}_{2}$ adsorption-desorption isotherms were measured by ASAP 2020 analyzer. The Co ion dissolved amount in the electrolyte was tested by the inductively coupled plasma optical emission spectrometry (ICP - OES).

\subsection{Electrochemical Measurements}

In this experiment, the electrochemical performance of $\mathrm{Ni}-\mathrm{Zn}$ alkaline battery in a mixture of $4 \mathrm{M} \mathrm{KOH}+1 \mathrm{M}$ $\mathrm{K}_{2} \mathrm{CO}_{3}+2 \mathrm{M} \mathrm{KF}$ and saturated $\mathrm{ZnO}, \mathrm{O}_{\mathrm{d}}$-CNO@Ni NTs and commercial zinc were used as cathode and anode, respectively. The Chenhua electrochemical workstation (CHI760E) was used for cyclic voltammetry (CV), galvanostatic charge-discharge (GCD) and electrochemical impedance spectroscopy (EIS) tests. Rate performance and cycle life were measured using the NEWARE battery test system (NEWARE, PR China). In the three-electrode electrochemical test using CHI760E, the nickel foam containing active material was directly prepared as working electrode, and saturated calomel electrode (SCE) was used as the reference electrode and platinum electrode $(\mathrm{Pt})$ was used as the counter electrode.

The energy density $\mathrm{E}\left(\mathrm{Wh} \mathrm{kg}^{-1}\right)$ and power density $\mathrm{P}$ $\left(\mathrm{kW} \mathrm{kg}^{-1}\right)$ are obtained by following:

$E=\frac{I \int U \mathrm{~d} t}{m}$ 
$P=\frac{E}{t}$

where $I$ is the discharge current $(\mathrm{mA}), U$ is the discharge voltage $(\mathrm{V}), t$ is the discharge time (h), and $m$ is the mass load of the active materials (mg).

\subsection{Calculation Methods}

The first-principle calculations are performed using VASP code [34], based on density functional theory (DFT) [35, 36]. The CNO slab with (001) surface is chosen as calculation model. The $\boldsymbol{a}$ and $\boldsymbol{b}$ axes are $8.94 \AA \times 8.94 \AA$, while the $c$ axes are set to $35 \AA$ to ensure sufficient vacuum to avoid interactions between two cycles. By using the Purdue-Burke-Enzehoff (PBE) exchange-correlation functional, the general gradient approximation (GGA) is used to calculate the exchange-correlation energy [37]. The DFT $+\mathrm{U}$ method $[38,39]$ with strong correlation effects was adopted to describe the localization of Co-3d and Ni-3d electrons. The $\mathrm{U}-\mathrm{J}$ values of $\mathrm{Co}$ and $\mathrm{Ni}$ are 3.4 and $6.0 \mathrm{eV}$, respectively [40]. The influence of van der Waals interactions was estimated, and the optimal commutative van der Waals function DFT-D3 is realized [41]. The cutoff energy of the plane wave was $500 \mathrm{eV}$, and the $3 \times 3 \times 1$ and $5 \times 5 \times 1$ k-point grids in the Monkhorst Pack [42] sampling scheme were used for geometric optimization and computation of electronic properties, respectively. The convergence condition of energy is $10^{-4} \mathrm{eV}$, and the structures were relaxed until the force on each atom is less than $0.03 \mathrm{eV} \AA^{-1}$. Spin polarization is taken into account in all calculations, and structure mapping and charge density visualization were performed using VESTA [43].

The binding energies $E_{\mathrm{b}}$ of $\mathrm{OH}$ ion on the surfaces of $\mathrm{CNO}$ are defined as:

$E_{\mathrm{b}}=E_{\mathrm{CNO}+\mathrm{OH}}-\left(E_{\mathrm{CNO}}+E_{\mathrm{OH}}\right)$

$E_{\mathrm{OH}}=E\left(\mathrm{H}_{2} \mathrm{O}\right)-1 / 2 E\left(\mathrm{H}_{2}\right)$

here, $E_{\mathrm{CNO}+\mathrm{OH}}$ is the total energy of the CNO slab with an adsorbed $\mathrm{OH}, E_{\mathrm{CNO}}$ is the total energy of pristine $\mathrm{CNO}$ slab and $E_{\mathrm{OH}}$ is the total energy of $\mathrm{OH}$. And $E\left(\mathrm{H}_{2} \mathrm{O}\right)$ and $E\left(\mathrm{H}_{2}\right)$ are the total energy of $\mathrm{H}_{2} \mathrm{O}$ and $\mathrm{H}_{2}$ molecule, respectively.

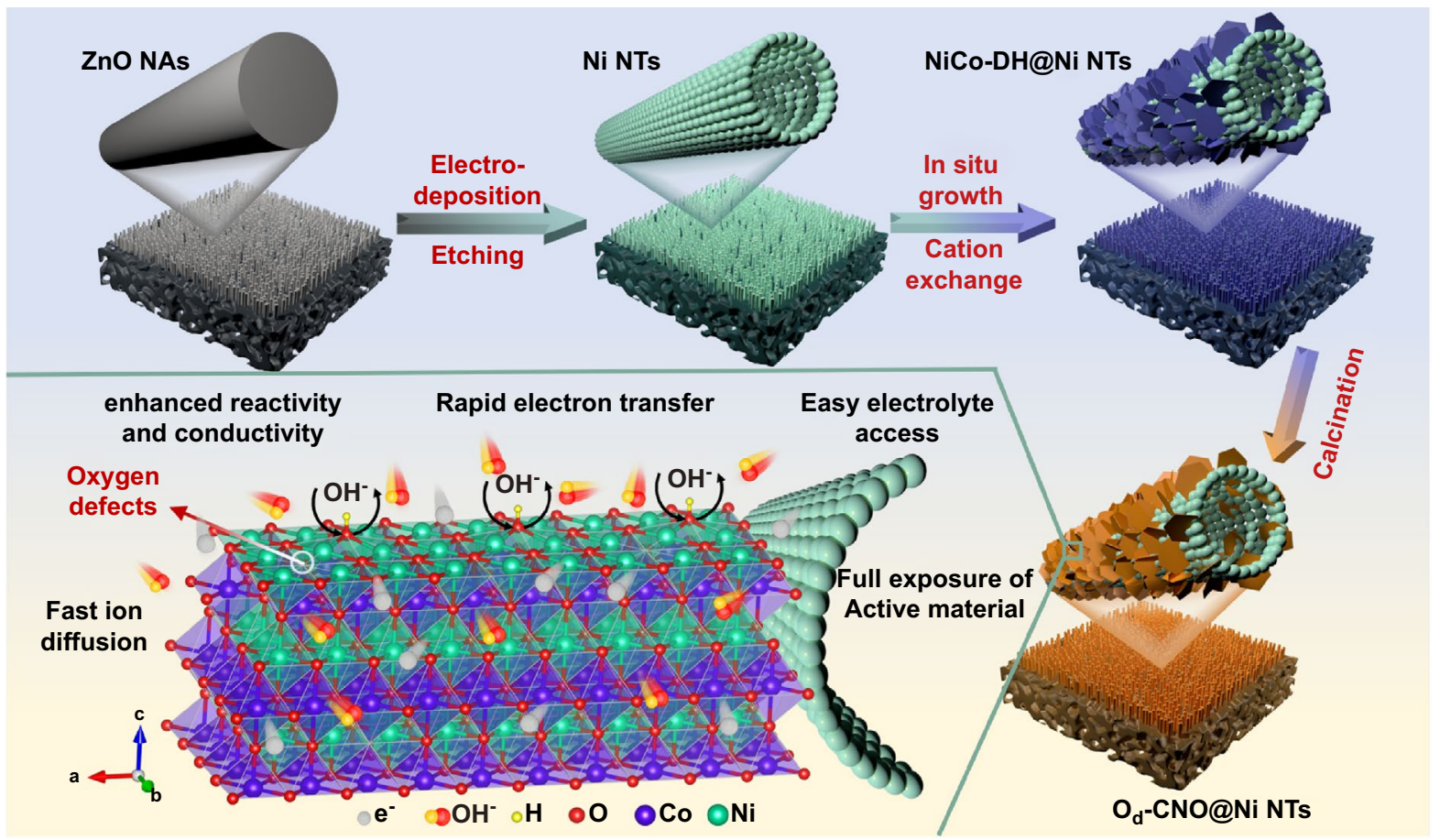

Fig. 1 Synthesis mechanism of $\mathrm{O}_{\mathrm{d}}-\mathrm{CNO} @ \mathrm{Ni}$ NTs nanostructure 


\section{Results and Discussion}

\subsection{Morphology and Structure}

Ultra-thin $\mathrm{CoNiO}_{2}$ nanosheets with oxygen defects were prepared on nickel nanotubes $\left(\mathrm{O}_{\mathrm{d}}-\mathrm{CNO} @ \mathrm{Ni} \mathrm{NTs}\right)$ as the cathode material by cation exchange method. The principle of the preparation process is shown in Fig. 1. Firstly, $\mathrm{ZnO}$ nanorod arrays ( $\mathrm{ZnO} \mathrm{NAs}$ ) were grown on pure nickel foam by hydrothermal method (Fig. S1a-c). The XRD peaks are well retrieved (PDF No. 36-1451, Fig. S1d). Then, uniform $\mathrm{Ni}$ films are electrodeposited. ZnO NAs were removed by etching, remaining the Ni NTs with hollow structures (PDF No. 04-0850, Figs. 2a and S2). Finally, the $\mathrm{O}_{\mathrm{d}}$-CNO nanostructure was prepared by in situ growth on Ni NTs. The Ni NTs are uniformly coated by interconnected ultrathin $\mathrm{O}_{\mathrm{d}}$-CNO nanosheets (Fig. 2b), and the size of a single nanosheet was about $200 \mathrm{~nm}$. As a comparison, SEM images of $\mathrm{CNO}$ and $\mathrm{O}_{\mathrm{d}^{-}} \mathrm{CNO}$ samples are shown in Fig. S3. In addition, the Brunauer-Emmett-Teller (BET) results further demonstrate the high specific surface area of $\mathrm{O}_{\mathrm{d}}-\mathrm{CNO} @$ Ni NTs (Fig. S4). Specifically, the specific surface area of $\mathrm{O}_{\mathrm{d}}$-CNO@Ni NTs $\left(52.25 \mathrm{~m}^{2} \mathrm{~g}^{-1}\right)$ was much higher than that of $\mathrm{O}_{\mathrm{d}}-\mathrm{CNO}\left(36.57 \mathrm{~m}^{2} \mathrm{~g}^{-1}\right)$ and $\mathrm{CNO}\left(35.84 \mathrm{~m}^{2} \mathrm{~g}^{-1}\right)$. The $\mathrm{O}_{\mathrm{d}}$-CNO@Ni NTs composite arrays combine the advantages of self-supporting Ni NTs and the abundant active sites of the $\mathrm{O}_{\mathrm{d}}$-CNO two-dimensional ultra-thin nanosheets, which
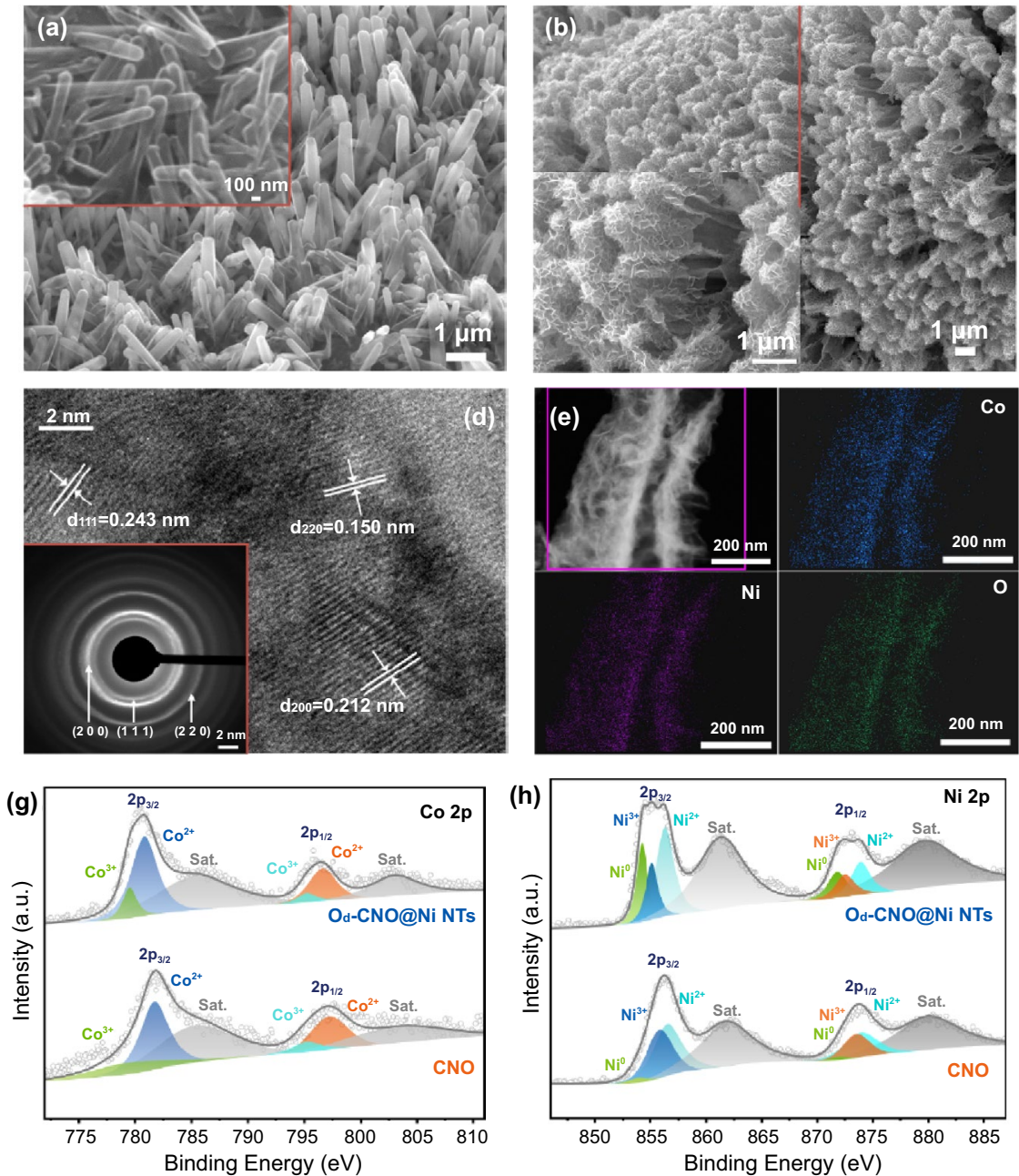
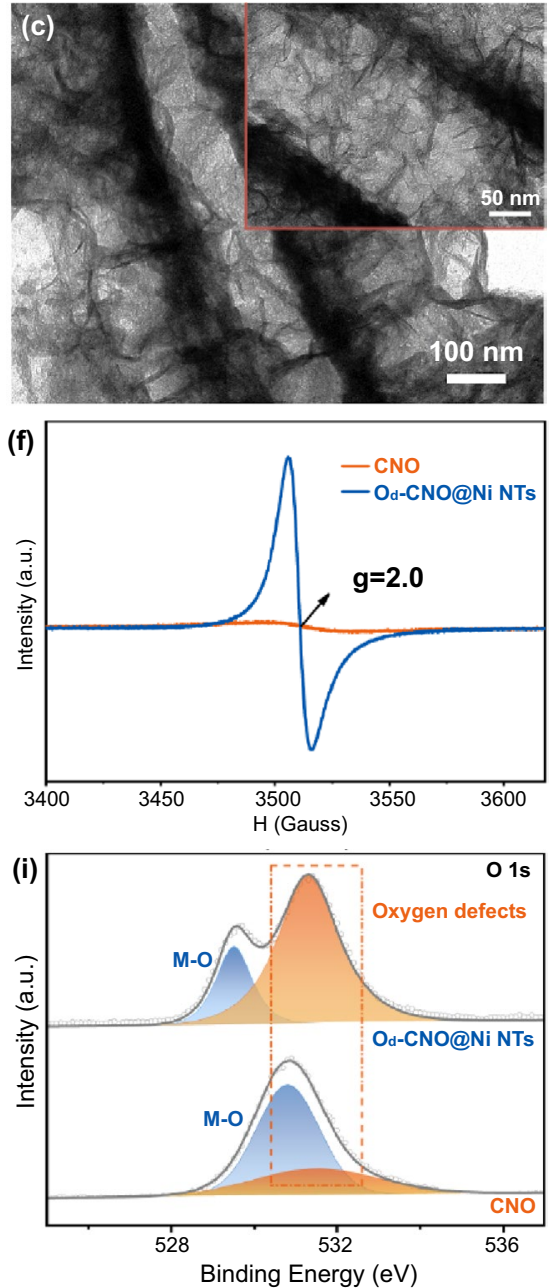

Fig. 2 Structure characterization of $\mathrm{O}_{d}-\mathrm{CNO} @ N i \mathrm{NTs}$. a, b SEM at high and low magnifications of Ni NTs and $\mathrm{O}_{\mathrm{d}}-\mathrm{CNO} @ \mathrm{Ni} N \mathrm{NT}$. c TEM images and d HRTEM images of $\mathrm{O}_{\mathrm{d}^{-}} \mathrm{CNO} @ \mathrm{Ni}$ NTs. e EDX element mappings of $\mathrm{O}_{\mathrm{d}^{-}} \mathrm{CNO} @ \mathrm{Ni}$ NTs. f EPR spectra of $\mathrm{O}_{\mathrm{d}}-\mathrm{CNO} @ \mathrm{Ni}$ NTs. g-i XPS of Co 2p, Ni 2p, and $\mathrm{O} 1 \mathrm{~s}$ for $\mathrm{O}_{\mathrm{d}}-\mathrm{CNO} @ \mathrm{Ni}$ NTs and $\mathrm{CNO}$ 
not only provides more active sites, but also reduces the ion transport distance [44].

To explore the structural differences caused by the introduction of oxygen defects, we also prepared $\mathrm{CNO}$ without oxygen defects (Fig. S5). Three diffraction peaks can be assigned to the (111), (200), and (220) crystal faces of CNO (PDF No. 10-0188) [45]. However, the intensity of diffraction peaks of the three main crystal planes of $\mathrm{O}_{\mathrm{d}} \mathrm{CNO}$ is weakened, which means that the crystallinity is weakened to some extent [23]. To further understand the microstructure of the samples, TEM was used to characterize. Figure $2 \mathrm{c}$ reveals the diameter of the Ni NTs is approximately $100 \mathrm{~nm}$. The lattice fringes can be seen under HRTEM (Fig. 2d). Concretely, compared with CNO, the lattice fringe spacing of $\mathrm{O}_{\mathrm{d}}$-CNO has no significant change, which is $d_{(111)}=0.243 \mathrm{~nm}, d_{(200)}=0.211 \mathrm{~nm}$, and $d_{(220)}=0.150 \mathrm{~nm}$, respectively. This corresponds to three faintly bright diffractive concentric rings in the SAED pattern (illustration of Fig. 2d), while that of CNO (Fig. S6) are clearer and brighter. As a result, this is consistent with the abovementioned characterization result in Fig. S5. According to the energy-dispersive EDX of $\mathrm{O}_{\mathrm{d}}$-CNO@ Ni NTs in Fig. 2e, Ni, $\mathrm{Co}$, and $\mathrm{O}$ are evenly distributed on the nanosheet (Fig. S7 and Table S2). The optical photograph of the composite electrode also shows the uniform distribution of the electrode material on the nickel foam (Fig. S8).

The results of electron paramagnetic resonance (EPR) analysis (Fig. 2f), the oxygen defects characteristic (g factor is a peak signal of 2.0) was generated in $\mathrm{O}_{\mathrm{d}^{-}} \mathrm{CNO} @ \mathrm{Ni}$ NTs lattice [46]. To further prove the existence of oxygen defects and analyze the valence state of each element, the XPS analysis of $\mathrm{O}_{\mathrm{d}^{-}} \mathrm{CNO} @ \mathrm{Ni}$ NTs was carried out. The XPS survey spectrum (Fig. S9) shows $\mathrm{Co}, \mathrm{Ni}, \mathrm{O}$, and $\mathrm{C}$, which are the main elemental of $\mathrm{O}_{\mathrm{d}}-\mathrm{CNO} @ \mathrm{Ni}$ NTs. Figure $2 \mathrm{~g}$ demonstrates two typical Co $2 \mathrm{p}_{1 / 2}$ and Co $2 \mathrm{p}_{3 / 2}$ orbitals of the $\mathrm{CNO}$ phase. It shows that the Co state exists in the form of $\mathrm{Co}^{2+}$ and $\mathrm{Co}^{3+}$ [47]. The $\mathrm{Ni} 2 \mathrm{p}$ emission spectra of the $\mathrm{CNO}$ and $\mathrm{O}_{\mathrm{d}} \mathrm{CNO} @ \mathrm{Ni}$ NTs samples (Fig. 2h) show Ni $2 \mathrm{p}_{1 / 2}$ and $\mathrm{Ni} 2 \mathrm{p}_{3 / 2}$ of spin-orbit doublets [48]. For $\mathrm{O}_{\mathrm{d}} \mathrm{CNO} @ \mathrm{Ni}$ NTs, the peak intensity of $\mathrm{Ni}^{3+}$ is obviously weakened, and the binding energies are 855.2 and $872.9 \mathrm{eV}$, respectively, while the intensity of $\mathrm{Ni}^{2+}$ with binding energies of 856.5 and $873.9 \mathrm{eV}$ is increased, indicating that the reduction of $\mathrm{Ni}^{3+}$ to $\mathrm{Ni}^{2+}$ is related to sintering and annealing, thus confirming the generation of oxygen defects. In addition to $\mathrm{Ni}^{2+}$ and $\mathrm{Ni}^{3+}, \mathrm{Ni}^{0}$ exists in the valence state of $\mathrm{Ni}$, indicating that there are metallic Ni phase spots in $\mathrm{O}_{\mathrm{d}} \mathrm{CNO} @ \mathrm{Ni}$ NTs. It is easy to understand that the detected $\mathrm{Ni}^{0}$ is mainly the presence of elemental nickel in the foamed nickel substrate and part of Ni NTs. Figure 2i is a comparative O 1s XPS spectrum of $\mathrm{CNO}$ and $\mathrm{O}_{\mathrm{d}}-\mathrm{CNO} @ \mathrm{Ni}$ NTs samples. The peak intensity (M-O) at $529.8 \mathrm{eV}$ mainly corresponds to the host lattice oxygen in $\mathrm{O}_{\mathrm{d}}-\mathrm{CNO} @ \mathrm{Ni} \mathrm{NTs}(\mathrm{Co}-\mathrm{O} / \mathrm{Ni}-\mathrm{O})$. In particular, a more obvious peak intensity appears at $531.3 \mathrm{eV}$, which is related to the bonding state of the defect $\mathrm{O}$ [49].

\subsection{Electrochemical Performance of the Electrode}

The $\mathrm{O}_{\mathrm{d}}-\mathrm{CNO} @ \mathrm{Ni}$ NTs electrochemical performance was characterized in a three-electrode system with $4 \mathrm{M}$ $\mathrm{KOH}$. Figure 3a shows the $\mathrm{CV}$ of Ni NTs, $\mathrm{CNO}, \mathrm{O}_{\mathrm{d}} \mathrm{CNO}$, and $\mathrm{O}_{\mathrm{d}}-\mathrm{CNO} @ \mathrm{Ni} \mathrm{NTs}$ were collected at $5.0 \mathrm{mV} \mathrm{s}^{-1}$ $(-0.1 \sim 0.6 \mathrm{~V})$. The $\mathrm{O}_{\mathrm{d}}-\mathrm{CNO} @ \mathrm{Ni}$ NTs electrode has a larger $\mathrm{CV}$ scanning area and higher response current $\left(4.8 \mathrm{~A} \mathrm{~g}^{-1}\right.$ of Ni NTs, $30.2 \mathrm{~A} \mathrm{~g}^{-1}$ of CNO, $40.5 \mathrm{~A} \mathrm{~g}^{-1}$ of $\mathrm{O}_{\mathrm{d}^{-}} \mathrm{CNO}$, $78.8 \mathrm{~A} \mathrm{~g}^{-1}$ of $\mathrm{O}_{\mathrm{d}^{-}} \mathrm{CNO} @ \mathrm{Ni} \mathrm{NTs}$ ), which confirms its higher capacity storage and electrochemical activity. This may be associated with the promotion of surface charge state and the enhancement of $\mathrm{OH}^{-}$adsorption energy caused by oxygen defects. Besides, compared with $\mathrm{CNO}$, the potential difference of cathodic peak and anodic peak of $\mathrm{O}_{\mathrm{d}}-\mathrm{CNO}$ and $\mathrm{O}_{\mathrm{d}}$-CNO@Ni NTs is much smaller, implying a lower electrochemical polarization for $\mathrm{O}_{\mathrm{d}}-\mathrm{CNO}$ or $\mathrm{O}_{\mathrm{d}} \mathrm{CNO} @ \mathrm{Ni}$ NTs. The CV area of the Ni NTs electrode is quite small, which indicates that the Ni NTs electrode has almost no capacity contribution. CV curves for $\mathrm{O}_{\mathrm{d}}-\mathrm{CNO} @ \mathrm{Ni}$ NTs electrodes from 2 to $60 \mathrm{mV} \mathrm{s}^{-1}$ (Fig. 3b), their good symmetrical distribution and similar shape indicate the stability and reversibility of the electrode. The extremely high current density of $\mathrm{O}_{\mathrm{d}} \mathrm{CNO} @ \mathrm{Ni}$ NTs electrodes indicates its excellent highpower potential.

To study the electrochemical kinetics of $\mathrm{O}_{\mathrm{d}}$-CNO@ $\mathrm{Ni}$ NTs electrodes, a typical couple of redox peaks match the adsorption/desorption process of $\mathrm{OH}^{-}$in the redox reaction. The specific reaction equation can be described as:

$\mathrm{CoNiO}_{2}+2 \mathrm{OH}^{-} \leftrightharpoons \mathrm{CoOOH}+\mathrm{NiOOH}+2 \mathrm{e}^{-}$

$\mathrm{CoOOH}+\mathrm{OH}^{-} \leftrightharpoons \mathrm{CoO}_{2}+\mathrm{H}_{2} \mathrm{O}+\mathrm{e}^{-}$

The diffusion-controlled redox reaction is revealed by the relation between the peak current density and scan rate 

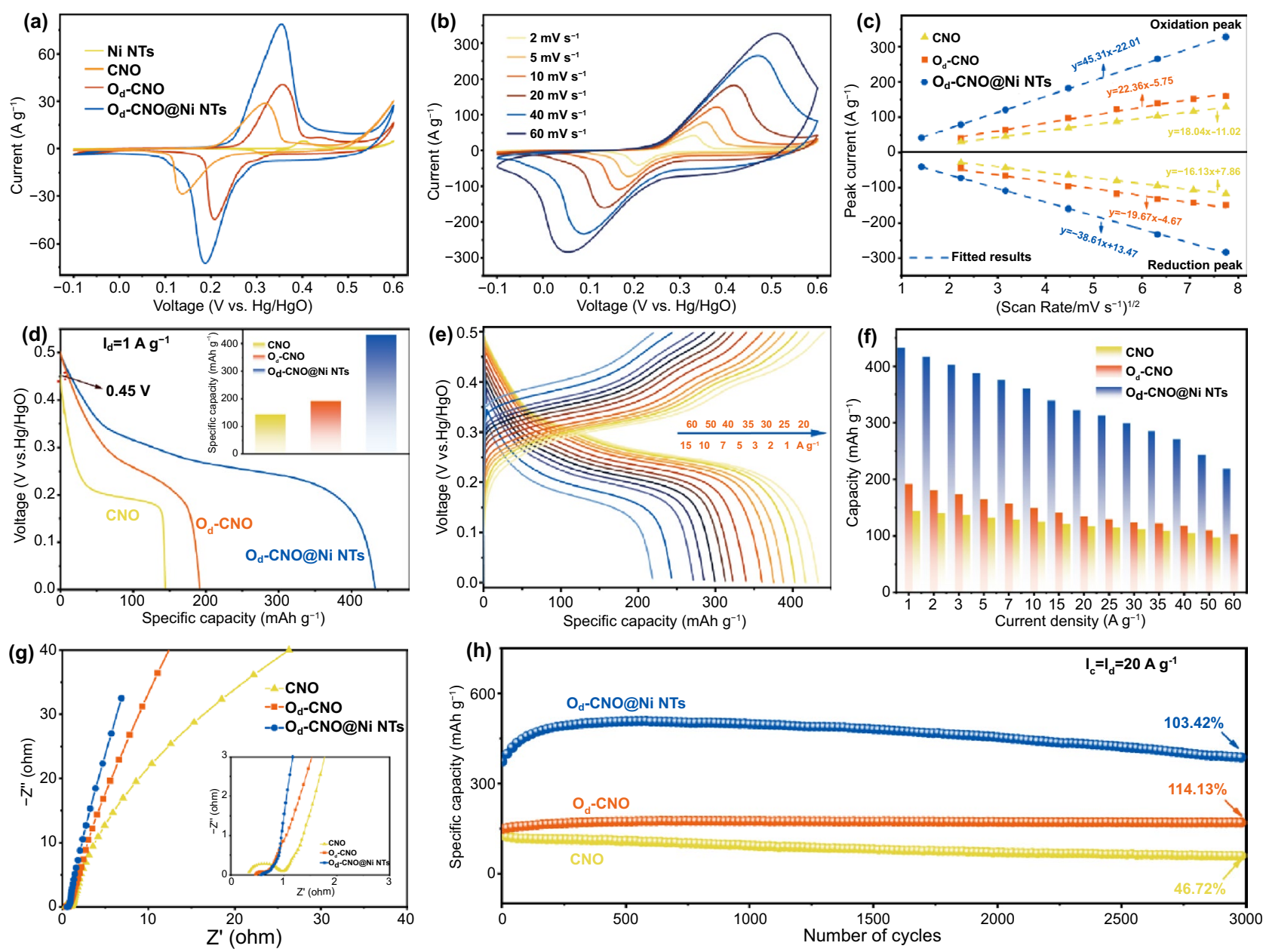

Fig. 3 Electrochemical evaluation of the cathodes. a Comparison of CV. b CV of the $\mathrm{O}_{\mathrm{d}}-\mathrm{CNO} @ \mathrm{Ni}$ NTs at different scan rates. $\mathbf{c}$ Correlation

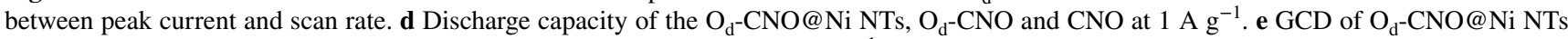
cathode. f Rate performance. $\mathbf{g}$ Nyquist plots. h Discharge capacity at $20.0 \mathrm{~A} \mathrm{~g}^{-1}$ for 3000 cycles

$\left(\mathrm{v}^{1 / 2}\right)$ is linear (Fig. 3c) [14]. Figure S10a-c shows the calculated contribution ratio of the three electrodes at various scan rates. For the $\mathrm{O}_{\mathrm{d}}-\mathrm{CNO} @ \mathrm{Ni}$ NTs electrode, $82 \%$ of the capacity is diffusive-controlled at $5 \mathrm{mV} \mathrm{s}^{-1}$ and gradually decreases to $51 \%$ at $40 \mathrm{mV} \mathrm{s}^{-1}$, exhibiting the main diffusive-controlled behavior. For $\mathrm{O}_{\mathrm{d}^{-}} \mathrm{CNO}$ electrode and $\mathrm{CNO}$ electrode, the capacitance contribution is more obvious. Therefore, the capacity decreases less as the current density increases, benefiting from the surface-control characteristics [33]. Electrochemical impedance spectroscopy (EIS) results also shed light on the enhanced electrochemical kinetics described above. Observed from the Nyquist plot (Fig. 3g), the corresponding equivalent circuit and its values are shown in Fig. S11 and Table S3. In the high-frequency region, a smaller semicircle (inset in Fig. $3 \mathrm{~g}$ ) is shown for $\mathrm{O}_{\mathrm{d}}$-CNO and $\mathrm{O}_{\mathrm{d}}-\mathrm{CNO} @ \mathrm{Ni}$ NTs electrodes, and their charge transfer resistance $R_{\mathrm{ct}}\left(0.40 \Omega\right.$ of $\mathrm{O}_{\mathrm{d}}-\mathrm{CNO}, 0.35 \Omega$ of $\mathrm{O}_{\mathrm{d}}-\mathrm{CNO} @ \mathrm{Ni}$ NTs) is almost half of the CNO electrode $(0.72 \Omega$ of $\mathrm{CNO})$. Furthermore, the slope of $\mathrm{O}_{\mathrm{d}^{-}} \mathrm{CNO}$ and the $\mathrm{O}_{\mathrm{d}^{-}} \mathrm{CNO} @ \mathrm{Ni}$ NTs is higher in the low frequency region, attributing to oxygen defects introduced in $\mathrm{CNO}$ to promote rapid charge transfer, improving the electrode conductivity during charging and discharging. Therefore, the $\mathrm{O}_{\mathrm{d}}-\mathrm{CNO} @ \mathrm{Ni}$ NTs electrode has an overwhelming advantage in terms of electrochemical performance.

Figure $3 \mathrm{~d}$ shows the comparison of discharge behavior of $\mathrm{CNO}, \mathrm{O}_{\mathrm{d}^{-}} \mathrm{CNO}$, and $\mathrm{O}_{\mathrm{d}^{-}} \mathrm{CNO} @ \mathrm{Ni} \mathrm{NTs}\left(\right.$ at $1 \mathrm{~A} \mathrm{~g}^{-1}$ ). Compared with the $\mathrm{CNO}(0.45 \mathrm{~V}), \mathrm{O}_{\mathrm{d}^{-}} \mathrm{CNO}$ and $\mathrm{O}_{\mathrm{d}}-\mathrm{CNO} @$ $\mathrm{Ni}$ NTs electrodes $(0.5 \mathrm{~V})$ have a larger potential voltage 
window (Fig. S12a-d). The $\mathrm{O}_{\mathrm{d}}-\mathrm{CNO} @ \mathrm{Ni}$ NTs electrode has a more ideal discharge potential platform. The specific capacity of $\mathrm{O}_{\mathrm{d}^{-}} \mathrm{CNO} @ \mathrm{Ni}$ NTs electrodes is as high as $432.7 \mathrm{mAh} \mathrm{g}^{-1}$ (at $1 \mathrm{~A} \mathrm{~g}^{-1}$ ), significantly larger than that of $\mathrm{O}_{\mathrm{d}}$-CNO electrodes (191.8 $\mathrm{mAh} \mathrm{g}^{-1}$ ) and CNO electrodes $\left(144.0 \mathrm{mAh} \mathrm{g}^{-1}\right)$. The GCD curves also indicate excellent charge storage capacity (Fig. 3e). The specific capacity reached 432.7, 416.4, 402.6, 387.7, 375.2, 360, 339.2, $322.3,312.5,299.2,284.9,271.1,243$, and $218.3 \mathrm{mAh} \mathrm{g}^{-1}$ at $1,2,3,5,7,10,15,20,25,30,35,40,50$ and $60 \mathrm{~A} \mathrm{~g}^{-1}$. The capacity of $\mathrm{O}_{\mathrm{d}^{-}} \mathrm{CNO} @ \mathrm{Ni}$ NTs electrode still retains $218.3 \mathrm{mAh} \mathrm{g}^{-1}$ at $60 \mathrm{~A} \mathrm{~g}^{-1}$, demonstrating an impressive rate performance. Comparing $\mathrm{O}_{\mathrm{d}} \mathrm{CNO}$ and $\mathrm{CNO}$ electrodes (Figs. 3f and S13a-b), the capacity of $\mathrm{O}_{\mathrm{d}}-\mathrm{CNO} @ \mathrm{Ni}$ NTs electrodes is more than twice that of them, which once again proves the significant effect of hollow Ni NTs on increasing the specific capacity. Furthermore, to solve the main bottlenecks hindering the practical application of alkaline ZBBs, the cycle stability of the $\mathrm{CNO}, \mathrm{O}_{\mathrm{d}}-\mathrm{CNO}$, and $\mathrm{O}_{\mathrm{d}}-\mathrm{CNO} @$ Ni NTs electrode was evaluated (Fig. $3 \mathrm{~h}$ ). The $\mathrm{O}_{\mathrm{d}}-\mathrm{CNO}$ and $\mathrm{O}_{\mathrm{d}^{-}} \mathrm{CNO} @ \mathrm{Ni}$ NTs electrodes showed impressive cycle capacity and structural stability after 3000 cycles (the capacity retention of the $\mathrm{O}_{\mathrm{d}}-\mathrm{CNO}$ and $\mathrm{O}_{\mathrm{d}}-\mathrm{CNO} @ \mathrm{Ni}$ NTs electrode were $114.1 \%$ and $103.4 \%$, respectively), whereas the capacity retention of CNO electrodes is only $46.7 \%$ after 3000 cycles. This serious capacity degradation is related to the deactivation and self-dissolution of the electrode material itself. Importantly, the inductively coupled plasma optical emission spectrometry (ICP-OES) analysis of the Co concentration in electrolyte shows that the most Co ions were dissolved in CNO after 2000 cycles (Fig. S14). Figure S15 shows the SEM of $\mathrm{O}_{\mathrm{d}}-\mathrm{CNO} @ \mathrm{Ni}$ NTs, $\mathrm{O}_{\mathrm{d}}$-CNO and CNO electrodes at 100, 500, and 2000 cycles, respectively. After the long-cycle of different cycles, the morphology of $\mathrm{CNO}$ has obvious changes of dissolution, which eventually leads to the collapse of the structure and sharp attenuation of the capacity (Figs. S15c and S16a-b). However, the morphology of the $\mathrm{O}_{\mathrm{d}}-\mathrm{CNO} @ \mathrm{Ni}$ NTs and $\mathrm{O}_{\mathrm{d}}-\mathrm{CNO}$ electrode has no obvious change; thus, the structure is stable. It can still be observed that the clear and orderly hollow tubular structure and ultra-thin nanosheets are coated on the Ni NTs. This once again confirms that oxygen defects can significantly enhance the stability of the material, and abundant nickel nanotubes increase the capacity.
DFT claculation is used to study the impact of oxygen defects on the structure and electronic property. Based on the optimized $\mathrm{O}_{\mathrm{d}}$-CNO model, the adsorption behavior of $\mathrm{OH}^{-}$was investigated, and the effects of electrochemical performances caused by defects were discussed (Fig. 4a). Two different $\mathrm{OH}^{-}$adsorption sites on the defective surface were considered as shown in Fig. 4b. Apparently, compared with the pristine $\mathrm{CNO}$ as shown in Fig. 4c, the introduction of oxygen defects (point defect type/main lattice oxygen defect) can enhance the adsorption of $\mathrm{OH}^{-}$with the decreased binding energies from -0.29 to -3.18 or $-1.01 \mathrm{eV}$, respectively, contributing to higher capacity and cycling stability of the electrode material. This is consistent with the above experimental analysis on the electrochemical performance. Meanwhile, from Bader analysis (Fig. 4b) [50], we found that the existence of oxygen defects could increase the charge transfer between electrode and $\mathrm{OH}^{-}$from 0.57 to 0.64 or $0.61 \mathrm{e}^{-}$, respectively, accounting for the improved adsorption of $\mathrm{OH}^{-}$by oxygen defects.

To further discuss the charge storage mechanism, the total density of states (TDOS) of CNO bulk (Fig. S17), the TDOS of the pristine and $\mathrm{O}_{\mathrm{d}}$-CNO surface (Fig. $4 \mathrm{~d}$ ), and the partial density of states (PDOS) of the Ni-3d orbits (Fig. 4e) are calculated. From the TDOS of CNO bulk, CNO material has a metallic property, benefit for the charge transport during the electrode reactions. As the surface is the main place for redox reactions, the electronic properties of $\mathrm{O}_{\mathrm{d}}$-CNO surface are discussed. It can be seen that the empty band above the Fermi energy level is mainly contributed by Ni-3d orbits. After the generation of oxygen defects, the Fermi energy level shifts to a higher energy level, resulting in more empty states near the Fermi energy level. Therefore, these empty states could store more charges, leading to a higher capacity. The intermediate adsorption behavior of $\mathrm{OH}^{-}$on the surface of the active material is very important for the reversible capacity of the electrode material [51]. With the combination of more available unoccupied states and the strong $\mathrm{OH}^{-}$adsorption capacity, the Faraday reversible redox reaction will be promoted, thereby improving the charge storage capacity [52]. The theoretical calculation agrees with our experimental results, indicating that oxygen defects can effectively modify the surface electronic structure and improve the binding energy, rendering faster kinetics and better electrochemical performance. 
(a)

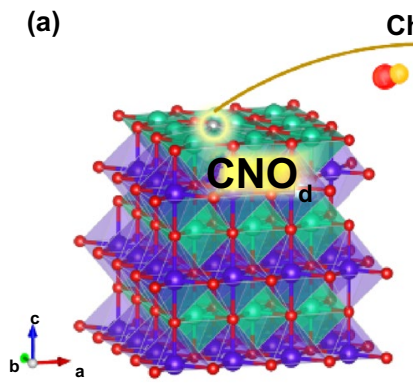

Charge

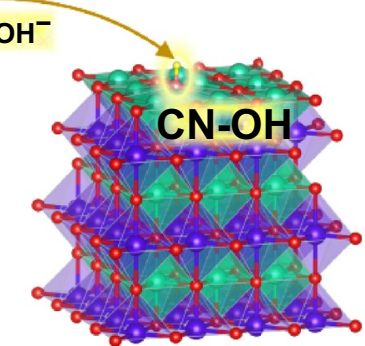

Site II @

(b)
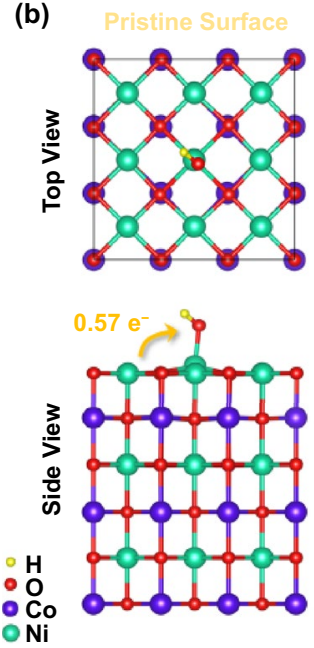

Site I@ Defective Surface
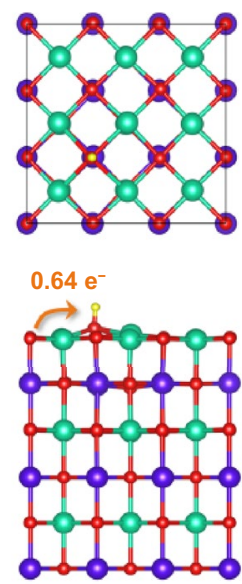
Defective Surface
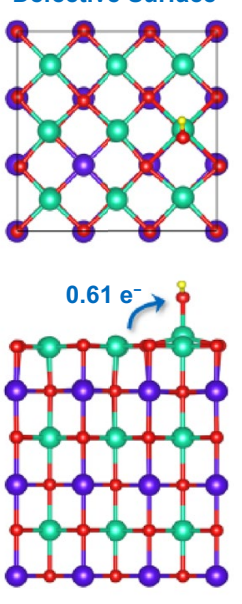

(c)

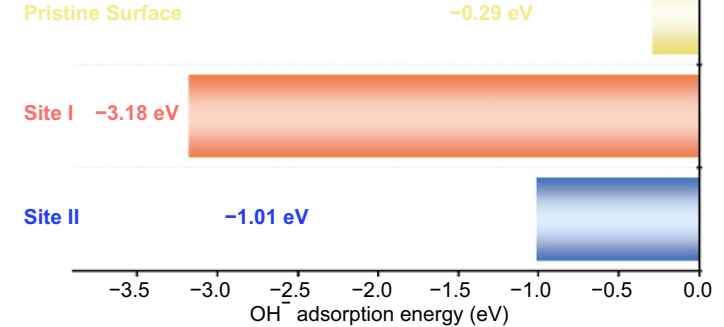

(d)
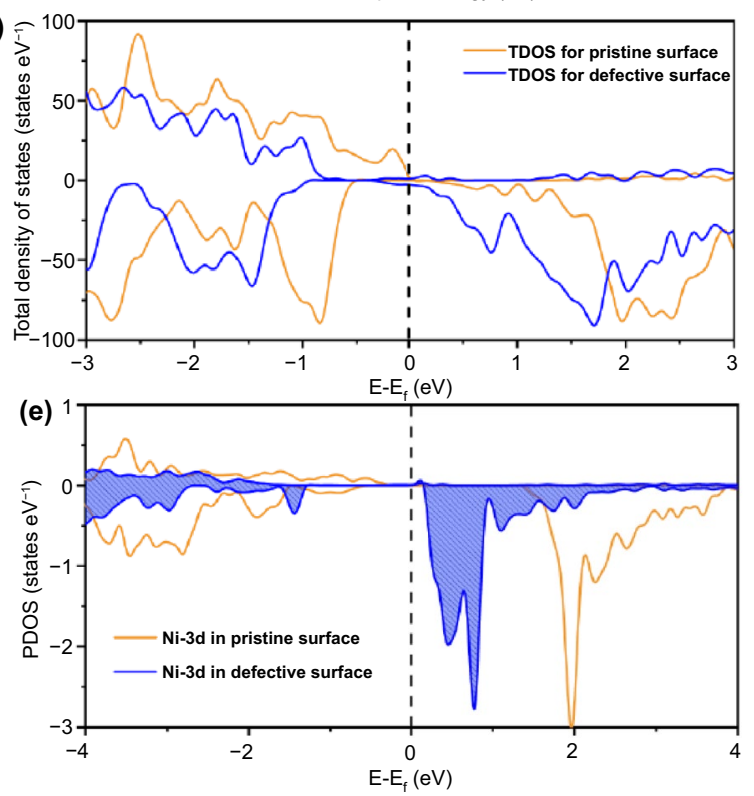

Fig. 4 a Modulation mechanism model of oxygen defects on $\mathrm{OH}^{-}$adsorption. b Surface charge transfer and $\mathrm{OH}^{-}$adsorption energy analysis. c Adsorption energy of $\mathrm{OH}^{-}$on CNO and $\mathrm{O}_{\mathrm{d}}$-CNO. d TDOS for CNO and $\mathrm{O}_{\mathrm{d}}-\mathrm{CNO}$. e PDOS for CNO and $\mathrm{O}_{\mathrm{d}^{-}}$CNO

\subsection{Evaluation of the $\mathrm{O}_{\mathrm{d}}$-CNO@Ni NTs//Zn Aqueous \\ Battery}

We use the $\mathrm{O}_{\mathrm{d}^{-}} \mathrm{CNO} @ \mathrm{Ni}$ NTs and zinc foil as cathode and counter electrode, the actual performance of the battery was evaluated in $4 \mathrm{M} \mathrm{KOH}+2 \mathrm{M} \mathrm{KF}+1 \mathrm{M} \mathrm{K}_{2} \mathrm{CO}_{3}+$ Sat. $\mathrm{ZnO}$
Cathode:

$\mathrm{CoNiO}_{2}+3 \mathrm{OH}^{-} \leftrightharpoons \mathrm{CoO}_{2}+\mathrm{NiOOH}+\mathrm{H}_{2} \mathrm{O}+3 \mathrm{e}^{-}$

Anode:

$\left[\mathrm{Zn}(\mathrm{OH})_{4}\right]^{2-}+2 \mathrm{e}^{-} \leftrightharpoons \mathrm{Zn}+4 \mathrm{OH}^{-}$

Overall:

$2 \mathrm{CoNiO}_{2}+3\left[\mathrm{Zn}(\mathrm{OH})_{4}\right]^{2-} \leftrightharpoons 2 \mathrm{NiOOH}+2 \mathrm{CoO}_{2}+3 \mathrm{Zn}+2 \mathrm{H}_{2} \mathrm{O}+6 \mathrm{OH}^{-}$

electrolyte. To explore the energy storage mechanism of $\mathrm{O}_{\mathrm{d}}$-CNO@Ni NTs//Zn battery, we conducted a series of ex situ tests, such as ex situ SEM (Fig. S18), ex situ XRD (Fig. S19), ex situ XPS (Fig. S20), and ex situ TEM (Fig. S21). The mechanism of the battery can be understood as following equation $[19,22-25]$ :
Figure 5a illustrates the $\mathrm{CV}$ of $1-30 \mathrm{mV} \mathrm{s}^{-1}(1.2-2 \mathrm{~V})$ for $\mathrm{O}_{\mathrm{d}}-\mathrm{CNO} @ \mathrm{Ni} \mathrm{NTs} / / \mathrm{Zn}$ aqueous battery. At $1 \mathrm{mV} \mathrm{s}^{-1}$, the $\mathrm{O}_{\mathrm{d}} \mathrm{CNO} @ \mathrm{Ni} \mathrm{NTs} / / \mathrm{Zn}$ battery exhibits good symmetrical redox peaks $(1.81 / 1.64 \mathrm{~V})$. Even at $30 \mathrm{mV} \mathrm{s}^{-1}$, it still remains symmetric $(1.96 / 1.52 \mathrm{~V})$, which means that the battery has excellent reversibility. Meanwhile, the form of the $\mathrm{CV}$ curve remained almost does not change at different scanning rates 

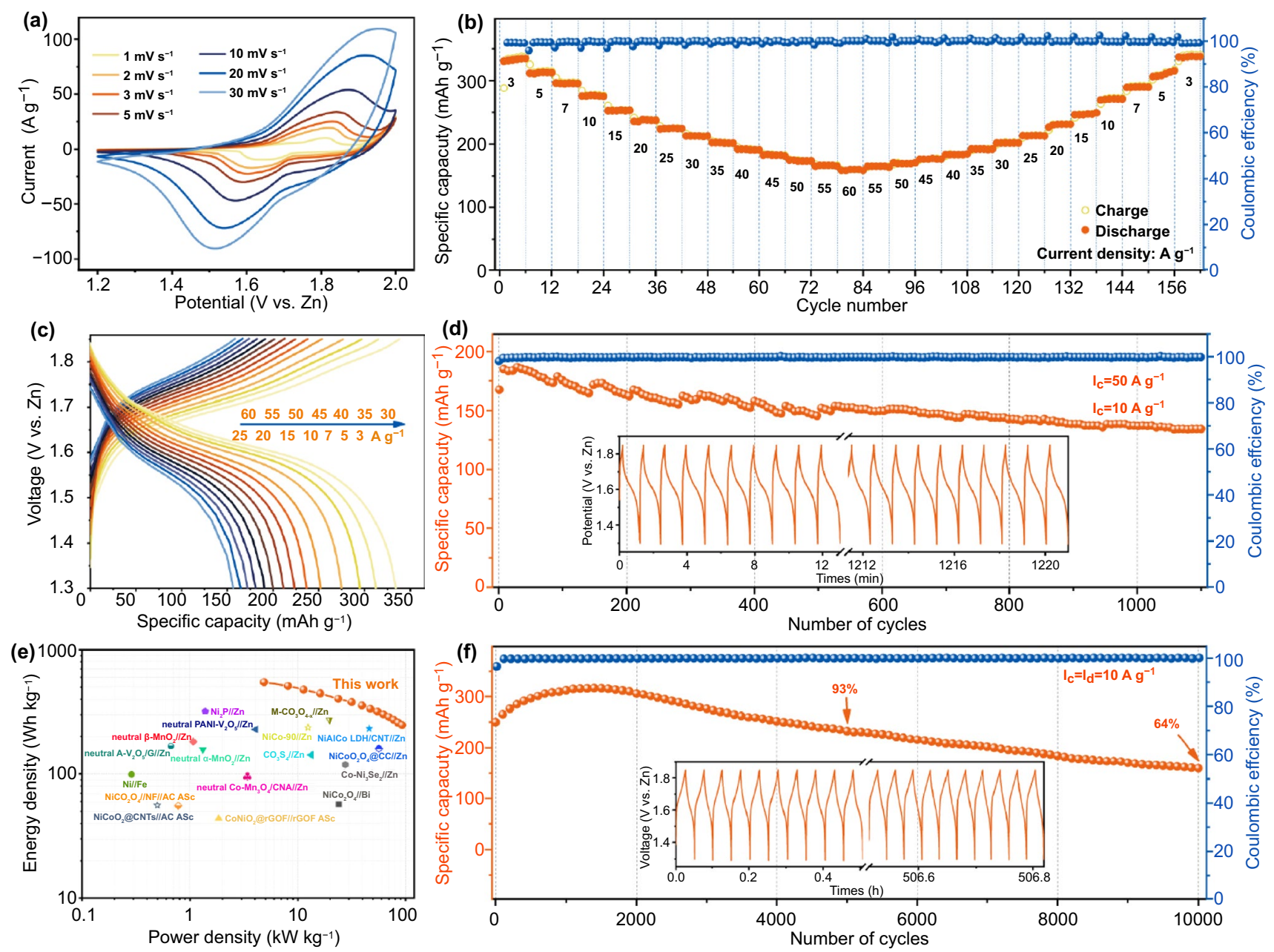

Fig. 5 Electrochemical performance of the battery. a CV profiles. b Rate performance and coulombic efficiency. $\mathbf{c}$ GCD curves. $\mathbf{d}$ Cyclic performance and coulomb efficiency at fast charge and slow discharge. The illustration displays the time-voltage curves at the first and last 10 cycles. e Ragone plot comparing the performance values of the $\mathrm{O}_{\mathrm{d}} \mathrm{CNO} @ \mathrm{Ni} \mathrm{NTs} / / \mathrm{Zn}$ battery with those of other ZBBs. f Cycling performance of the $\mathrm{Ni} / / \mathrm{Zn}$ battery. The illustration displays the time-voltage curves at the first and last 10 cycles

(1-30 $\left.\mathrm{mV} \mathrm{s}^{-1}\right)$, proving the battery has excellent stability. Figure $5 \mathrm{~b}$ shows the battery's rate capability and coulomb efficiency. The extremely high coulombic efficiency indicates that the battery is ability of rapid charge transfer and ion diffusion. Importantly, the $\mathrm{O}_{\mathrm{d}}$-CNO@Ni NTs//Zn battery exhibits high capacity of 334.9, 313.4, 296.3, 277.0, 253.3, $238.3,225.0,212.5,202.2,192.2,183.8,175.0,166.5$, and $160.0 \mathrm{mAh} \mathrm{g}^{-1}$ when at $3,5,7,10,15,20,25,30,35,40$, $45,50,55$, and $60 \mathrm{~A} \mathrm{~g}^{-1}$, respectively. The average discharge capacity can be restored when switching to $3 \mathrm{~A} \mathrm{~g}^{-1}$ after 156 cycles, which indicates that $\mathrm{O}_{\mathrm{d}}-\mathrm{CNO} @ \mathrm{Ni} \mathrm{NTs} / / \mathrm{Zn}$ battery has an extraordinary rate and reversible stability. Figure $5 \mathrm{c}$ shows the GCD curve of the $\mathrm{O}_{\mathrm{d}}$-CNO@ Ni NTs//Zn battery at different current density, showing a flat output voltage $(1.62 \mathrm{~V})$. The $\mathrm{O}_{\mathrm{d}^{-}} \mathrm{CNO} @ \mathrm{Ni} \mathrm{NTs} / / \mathrm{Zn}$ aqueous battery can be effectively charged/discharged in about $9.5 \mathrm{~s}$ at an extremely high current density (Fig. S22). It still maintains a high capacity of $158.3 \mathrm{mAh} \mathrm{g}^{-1}$ (at $60 \mathrm{~A} \mathrm{~g}^{-1}$ ), implying its ultra-fast properties, providing the possibility of achieving fast charging. Further, Fig. $5 \mathrm{~d}$ is a graph of the cycle performance of the $\mathrm{O}_{\mathrm{d}}$-CNO@Ni NTs//Zn battery under fast charge $\left(50 \mathrm{~A} \mathrm{~g}^{-1}\right)$ and slow discharge $\left(10 \mathrm{~A} \mathrm{~g}^{-1}\right)$ conditions. After 1100 cycles (approximately $20.3 \mathrm{~h}$ ), the capacity retention still exceeded $80 \%$. Comparing the GCD curve before and after the cycle (inset in Fig. 5d), there is no obvious change before and after the cycle, indicating the excellent 
stability of $\mathrm{O}_{\mathrm{d}}$-CNO@ Ni NTs//Zn battery under fast charge and slow discharge. It again demonstrates that hollow nickel nanotubes and abundant oxygen defects enhance the stability of the material during rapid charging and slow discharge repeatedly. Such excellent performance is almost unreported in current ZBBs.

An ultra-long cycle is realized in the $\mathrm{O}_{\mathrm{d}}-\mathrm{CNO} @ \mathrm{Ni}$ NTs//Zn battery (Fig. 5f). After multiple electrochemical activations, the coulombic efficiency remains nearly $100 \%$. Moreover, as calculated, after 5000 cycles, the $\mathrm{O}_{\mathrm{d}^{-}} \mathrm{CNO} @ \mathrm{Ni} \mathrm{NTs} / / \mathrm{Zn}$ battery at $10 \mathrm{~A} \mathrm{~g}^{-1}$ with a capacity of $232.7 \mathrm{mAh} \mathrm{g}^{-1}$, which is $93 \%$ of the initial average capacity. After 10,000 cycles (approximately 22 days), the cycle stability reached 64\%. Furthermore, the Ragone plot compares $\mathrm{O}_{\mathrm{d}}-\mathrm{CNO} @ \mathrm{Ni} \mathrm{NTs} / / \mathrm{Zn}$ battery with the most advanced aqueous electrochemical system. Encouragingly, in Fig. 5e, our work proposes a maximum energy density is $547.5 \mathrm{Wh} \mathrm{kg}^{-1}$ (based on the mass of the $\mathrm{O}_{\mathrm{d}}-\mathrm{CNO}$ @ Ni NTs cathode), and a maximum power density is $92.9 \mathrm{~kW} \mathrm{~kg}^{-1}$. This performance is better than almost all reported aqueous ZBBs, including, alkaline Ni-Zn [53], Co-Zn [19], Ni-Bi [54], Ni-Fe batteries [55], neutral $\mathrm{Zn}-\mathrm{Mn}$ [56], Zn-V batteries [57]. Besides, we noticed that supercapacitors also use nickel and cobalt bases as cathodes. In contrast, the energy density of supercapacitors is very low [58]. (a)
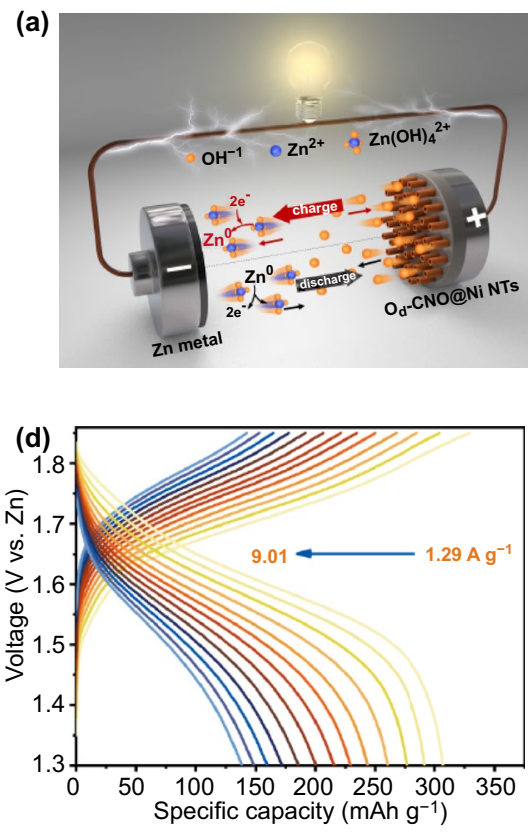
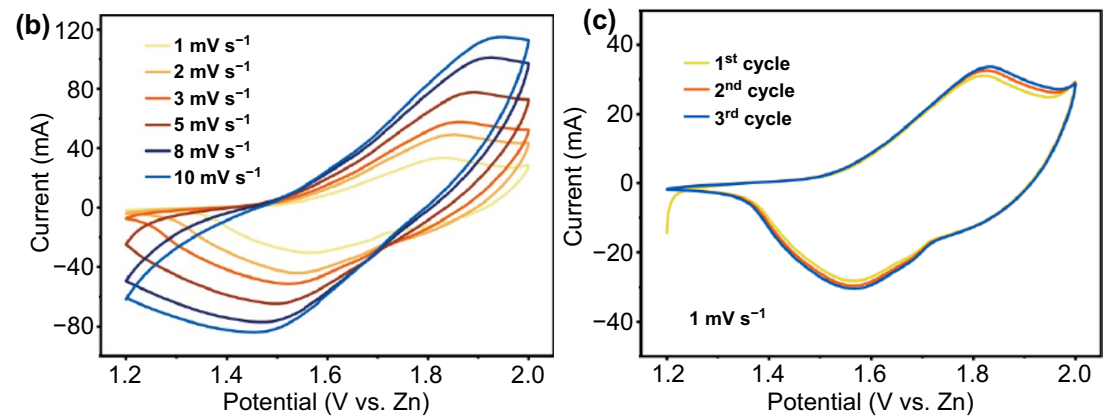

(e)

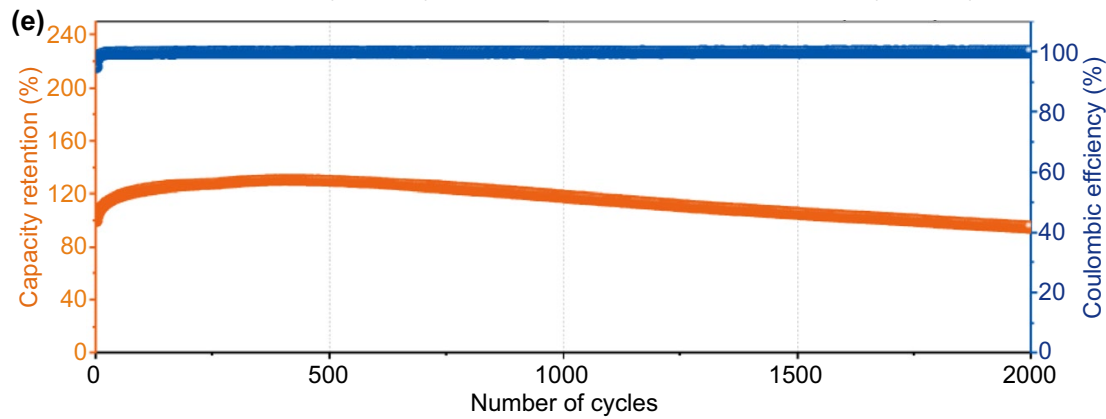

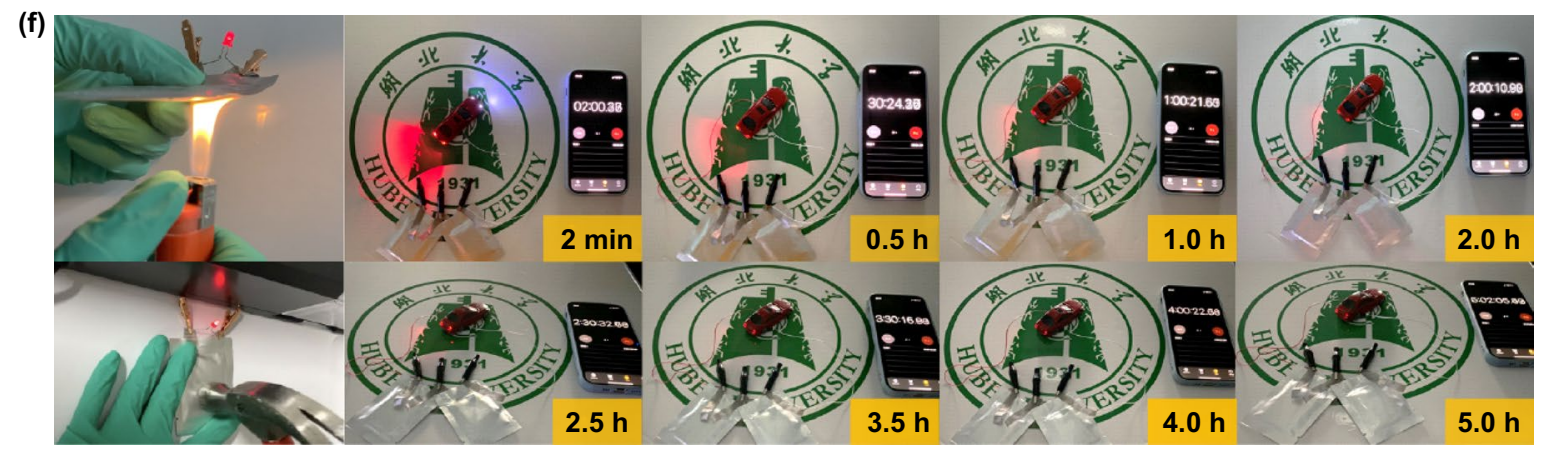

Fig. 6 a Schematic illustration of the $\mathrm{O}_{\mathrm{d}}-\mathrm{CNO} @ \mathrm{Ni}$ NTs//Zn battery. The $\mathrm{O}_{\mathrm{d}}$-CNO@Ni NTs//Zn soft-pack battery b CV profiles. c CV curves for the first three cycles at $1 \mathrm{mV} \mathrm{s}^{-1}$. d GCD profiles. e Cycle stability at $5 \mathrm{~A} \mathrm{~g} \mathrm{~g}^{-1}$. f Photograph of safety tests and powering a $3 \mathrm{~V}$ model car 


\subsection{Evaluation of the $\mathrm{O}_{\mathrm{d}}-\mathrm{CNO} @ \mathrm{Ni} \mathrm{NTs} / / \mathrm{Zn}$ Soft-Pack Battery}

Finally, in order to verify the possibility of application in real life, a soft-pack $\mathrm{O}_{\mathrm{d}}$-CNO@Ni NTs//Zn battery was prepared. The configuration illustration of soft-pack battery is shown in Fig. 6a. As shown in the CV curves in Fig. $6 \mathrm{~b}, \mathrm{c}$ and $\mathrm{S} 23$, the redox peak represents the electrochemical process. The soft-pack battery is also capable of achieving high rate performance and long cycle life. At the current density of $1.29,1.93,2.58,3.22,3.86,4.51$, $5.15,5.79,6.44,7.08,7.73,8.37$, and $9.01 \mathrm{~A} \mathrm{~g}^{-1}$, the high capacity of $307.22,291.84,276.25,260.19,243.56$, 229.07, 216.02, 199.89, 185.44, 171.72, 159.44, 148.08, and $138.19 \mathrm{mAh} \mathrm{g}^{-1}$, respectively (Fig. 6d). The capacity retention is still above $90 \%$ after 2000 cycles at $5 \mathrm{~A} \mathrm{~g}^{-1}$ (Fig. 6e). As a result, $3 \mathrm{~V}$ car lights are selected as the load for the two series soft-pack batteries. The car lights are very bright and can be kept on for more than $5 \mathrm{~h}$ (Fig. 6f). More importantly, comparing the CV before and after exposure to fire and hammer (Fig. S24a-b), the soft-pack battery can work continuously and stably under fire and hammer test (Fig. 6f, Videos S1 and S2). No danger of fire and blast, showing excellent reliability and security.

\section{Conclusion}

In summary, this work developed a three-dimensional hierarchical structure with ordered vertical nanotubes arrays and defective nanosheets, which greatly enhanced the electrochemical performance. Specifically, the existence of Ni NTs can increase ion diffusion channels and shorten ion migration distance, thereby having high conductivity and abundant active sites. More importantly, oxygen defects effectively improve the electrochemical kinetics of the cathode, make the electrode maintain good reversibility for a long time, and improve the surface electronic state structure of $\mathrm{O}_{\mathrm{d}^{-}} \mathrm{CNO} @ \mathrm{Ni}$ NTs, thus exhibiting strong $\mathrm{OH}^{-}$adsorption capacity. As a result, the $\mathrm{O}_{\mathrm{d}^{-}} \mathrm{CNO} @ \mathrm{Ni}$ NTs cathode shows improved specific capacity (432.7 $\mathrm{mAh} \mathrm{g}^{-1}$ ) and extraordinary rate performance $\left(218.3 \mathrm{mAh} \mathrm{g}^{-1}\right.$ at $\left.60 \mathrm{~A} \mathrm{~g}^{-1}\right)$. The capacity of the prepared $\mathrm{O}_{\mathrm{d}^{-}} \mathrm{CNO} @ \mathrm{Ni} \mathrm{NTs} / / \mathrm{Zn}$ rechargeable battery is $334.9 \mathrm{mAh} \mathrm{g}^{-1}$, and the cycling stability is $93 \%$. At the same time, it still has a capacity retention of $80 \%$ under the condition of fast charge $\left(50 \mathrm{~A} \mathrm{~g}^{-1}\right)$ and slow discharge $\left(10 \mathrm{~A} \mathrm{~g}^{-1}\right)$ after 1100 cycles. Our battery can also work at high temperature and high pressure, which will bring immediate benefits to the development for next-generation high-safety commercial batteries.

Acknowledgements This work was supported by the National Natural Science Foundation of China (No. 52002122), the Science and Technology Department of Hubei Province (No. 2019AAA038), the Project funded by China Postdoctoral Science Foundation (No. 2021M690947) and the Wuhan Yellow Crane Talent Program (No. 2017-02).

Open Access This article is licensed under a Creative Commons Attribution 4.0 International License, which permits use, sharing, adaptation, distribution and reproduction in any medium or format, as long as you give appropriate credit to the original author(s) and the source, provide a link to the Creative Commons licence, and indicate if changes were made. The images or other third party material in this article are included in the article's Creative Commons licence, unless indicated otherwise in a credit line to the material. If material is not included in the article's Creative Commons licence and your intended use is not permitted by statutory regulation or exceeds the permitted use, you will need to obtain permission directly from the copyright holder. To view a copy of this licence, visit http://creativecommons.org/licenses/by/4.0/.

Supplementary Information The online version contains supplementary material available at https://doi.org/10.1007/ s40820-021-00699-z.

\section{References}

1. B. Dunn, H. Kamath, J.M. Tarascon, Electrical energy storage for the grid: a battery of choices. Science 334, 928-935 (2011). https://doi.org/10.1126/science.1212741

2. Z.P. Cano, D. Banham, S. Ye, A. Hintennach, J. Lu et al., Batteries and fuel cells for emerging electric vehicle markets. Nat. Energy 3, 279-289 (2018). https://doi.org/10.1038/ s41560-018-0108-1

3. L. Shan, S. Liang, B. Tang, J. Zhou, Development and challenges of aqueous rechargeable zinc batteries. Sci. Bull. 65 , 3562-3584 (2020). https://doi.org/10.1360/TB-2020-0352

4. D. Chao, W. Zhou, F. Xie, C. Ye, H. Li et al., Roadmap for advanced aqueous batteries: from design of materials to applications. Adv. Sci. 6, eaba4098 (2020). https://doi.org/10.1126/ sciadv.aba4098

5. H. Li, D. Chao, B. Chen, X. Chen, C. Chuah et al., Revealing principles for design of lean-electrolyte lithium metal anode via in situ spectroscopy. J. Am. Chem. Soc. 142, 2012-2022 (2020). https://doi.org/10.1021/jacs.9b11774

6. C. Ye, Y. Jiao, D. Chao, T. Ling, J. Shan et al., Electron-state confinement of polysulfides for highly stable sodium-sulfur 
batteries. Adv. Mater. 32, 1907557-1907564 (2020). https:// doi.org/10.1002/adma.201907557

7. J. Huang, J. Zhou, S. Liang, Guest pre-intercalation strategy to boost the electrochemical performance of aqueous zinc-ion battery cathodes. Acta Phys. Chim. Sin. 37, 2005020 (2021). https://doi.org/10.3866/PKU.WHXB202005020

8. J. Gao, X. Xie, S. Liang, B. Lu, J. Zhou, Inorganic colloidal electrolyte for highly robust zinc-ion batteries. Nano-Micro Lett. 13, 1 (2021). https://doi.org/10.1007/ s40820-020-00525-y

9. G.G. Yadav, J.W. Gallaway, D.E. Turney, M. Nyce, J. Huang et al., Regenerable $\mathrm{Cu}$-intercalated $\mathrm{MnO}_{2}$ layered cathode for highly cyclable energy dense batteries. Nat. Commun. 8, 14424 (2017). https://doi.org/10.1038/ncomms 14424

10. C. Li, Q. Zhang, J. Sun, T. Li, S. Eagan et al., High-performance quasi-solid-state flexible aqueous rechargeable $\mathrm{Ag}-\mathrm{Zn}$ battery based on metal-organic framework-derived Ag nanowires. ACS Energy Lett. 3, 2761-2768 (2018). https://doi.org/ 10.1021/acsenergylett.8b01675

11. Y. Jian, D. Wang, M. Huang, H.-L. Jia, J. Sun et al., Facile synthesis of $\mathrm{Ni}(\mathrm{OH})_{2}$ /carbon nanofiber composites for improving nizn battery cycling life. ACS Sustain. Chem. Eng. 5, 68276834 (2017). https://doi.org/10.1021/acssuschemeng.7b01048

12. C. Xu, J. Liao, C. Yang, R. Wang, D. Wu et al., An ultrafast, high capacity and superior longevity $\mathrm{Ni} / \mathrm{Zn}$ battery constructed on nickel nanowire array film. Nano Energy 30, 900-908 (2016). https://doi.org/10.1016/j.nanoen.2016.07.035

13. X. Wang, M. Li, Y. Wang, B. Chen, Y. Zhu et al., A Zn-NiO rechargeable battery with long lifespan and high energy density. J. Mater. Chem. A 3, 8280-8283 (2015). https://doi.org/ 10.1039/C5TA01947H

14. W. Zhou, J. He, D. Zhu, J. Li, Y. Chen, Hierarchical NiSe nanosheet arrays as a robust cathode toward superdurable and ultrafast Ni-Zn aqueous batteries. ACS Appl. Mater. Interfaces 12, 34931-34940 (2020). https://doi.org/10.1021/acsami. 0c08205

15. P. Hu, T. Wang, J. Zhao, C. Zhang, J. Ma et al., Ultrafast alkaline $\mathrm{Ni} / \mathrm{Zn}$ battery based on $\mathrm{Ni}$-foam-supported $\mathrm{Ni}_{3} \mathrm{~S}_{2}$ nanosheets. ACS Appl. Mater. Interfaces 7, 26396-26399 (2015). https://doi.org/10.1021/acsami.5b09728

16. L. Zhou, X. Zhang, D. Zheng, W. Xu, J. Liu et al., $\mathrm{Ni}_{3} \mathrm{~S}_{2} @$ PANI core-shell nanosheets as a durable and high-energy binder-free cathode for aqueous rechargeable nickel-zinc batteries. J. Mater. Chem. A 7, 10629-10635 (2019). https://doi. org/10.1039/C9TA00681H

17. Z. Lu, X. Wu, X. Lei, Y. Li, X. Sun, Hierarchical nanoarray materials for advanced nickel-zinc batteries. Inorg. Chem. Front. 2, 184-187 (2015). https://doi.org/10.1039/C4QI0 $0143 \mathrm{E}$

18. X. Wang, F. Wang, L. Wang, M. Li, Y. Wang et al., An aqueous rechargeable $\mathrm{Zn} / / \mathrm{Co}_{3} \mathrm{O}_{4}$ battery with high energy density and good cycling behavior. Adv. Mater. 28, 4904-4911 (2016). https://doi.org/10.1002/adma.201505370

19. C. Teng, F. Yang, M. Sun, K. Yin, Q. Huang et al., Structural and defect engineering of cobaltosic oxide nanoarchitectures as an ultrahigh energy density and super durable cathode for
Zn-based batteries. Chem. Sci. 10, 7600-7609 (2019). https:// doi.org/10.1039/C9SC01902B

20. S. Zhang, B. Yin, Y. Luo, L. Shen, B. Tang et al., Fabrication and theoretical investigation of cobaltosic sulfide nanosheets for flexible aqueous Zn/Co batteries. Nano Energy 68, 104314 (2019). https://doi.org/10.1016/j.nanoen.2019.104314

21. H. Chen, Z. Shen, Z. Pan, Z. Kou, X. Liu et al., Hierarchical micro-nano sheet arrays of nickel-cobalt double hydroxides for high-rate Ni-Zn batteries. Adv. Sci. 6, 1802002 (2019). https:// doi.org/10.1002/advs.201802002

22. W. He, S. Wang, Y. Shao, Z. Kong, H. Tu et al., Water invoking interface corrosion: an energy density booster for $\mathrm{Ni} / / \mathrm{Zn}$ battery. Adv. Energy Mater. 11, 2003268 (2021). https://doi. org/10.1002/aenm.202003268

23. Y. Zeng, Z. Lai, Y. Han, H. Zhang, S. Xie et al., Oxygenvacancy and surface modulation of ultrathin nickel cobaltite nanosheets as a high-energy cathode for advanced $\mathrm{Zn}$-ion batteries. Adv. Mater. 30, 1802396 (2018). https://doi.org/10. 1002/adma.201802396

24. W. Shang, W. Yu, P. Tan, B. Chen, H. Xu et al., A highperformance $\mathrm{Zn}$ battery based on self-assembled nanostructured $\mathrm{NiCo}_{2} \mathrm{O}_{4}$ electrode. J. Power Sources 421, 6-13 (2019). https://doi.org/10.1016/j.jpowsour.2019.02.097

25. H. Zhang, X. Zhang, H. Li, Y. Zhang, Y. Zeng et al., Flexible rechargeable $\mathrm{Ni} / / \mathrm{Zn}$ battery based on self-supported $\mathrm{NiCo}_{2} \mathrm{O}_{4}$ nanosheets with high power density and good cycling stability. Green Energy Environ. 3, 56-62 (2018). https://doi.org/10. 1016/j.gee.2017.09.003

26. J.F. Parker, C.N. Chervin, I.R. Pala, M. Machler, M.F. Burz et al., Rechargeable nickel-3D zinc batteries: an energy-dense, safer alternative to lithium-ion. Science 356, 415-418 (2017). https://doi.org/10.1126/science.aak9991

27. H. Li, L. Ma, C. Han, Z. Wang, Z. Liu et al., Advanced rechargeable zinc-based batteries: recent progress and future perspectives. Nano Energy 62, 550-587 (2019). https://doi. org/10.1016/j.nanoen.2019.05.059

28. M. Huang, M. Li, C. Niu, Q. Li, L. Mai, Recent advances in rational electrode designs for high-performance alkaline rechargeable batteries. Adv. Funct. Mater. 29, 1807847 (2019). https://doi.org/10.1002/adfm.201807847

29. Q.N. Zhu, Z.Y. Wang, J.W. Wang, X.Y. Liu, D. Yang et al., Challenges and strategies for ultrafast aqueous zinc-ion batteries. Rare Met. 40, 309-328 (2020). https://doi.org/10. 1007/s 12598-020-01588-x

30. W. Zhou, D. Zhu, J. He, J. Li, H. Chen et al., A scalable top-down strategy toward practical metrics of $\mathrm{Ni}-\mathrm{Zn}$ aqueous batteries with total energy densities of $165 \mathrm{wh} \mathrm{kg}^{-1}$ and 506 wh L ${ }^{-1}$. Energy Environ. Sci. 13, 4157-4167 (2020). https://doi.org/10.1039/D0EE01221A

31. J. Ji, H. Wan, B. Zhang, C. Wang, Y. Gan et al., $\mathrm{Co}^{2+} /{ }^{3+} /{ }^{4+}$-regulated electron state of $\mathrm{Mn}-\mathrm{O}$ for superb aqueous zinc-manganese oxide batteries. Adv. Energy Mater. 11, 2003203 (2020). https://doi.org/10.1002/aenm. 202003203

32. Y. Zhang, L. Tao, C. Xie, D. Wang, Y. Zou et al., Defect engineering on electrode materials for rechargeable 
batteries. Adv. Mater. 32, 1905923 (2020). https://doi.org/ 10.1002/adma.201905923

33. W. Liu, Y. Chen, Y. Wang, Q. Zhao, L. Chen et al., Influence of anion substitution on 3D-architectured Ni-Co-A $(A=H$, $\mathrm{O}, \mathrm{P}$ ) as efficient cathode materials towards rechargeable $\mathrm{Zn}$ based battery. Energy Storage Mater. 37, 336-344 (2021). https://doi.org/10.1016/j.ensm.2021.02.026

34. G. Kresse, J. Hafner, Ab initio molecular-dynamics simulation of the liquid-metal-amorphous-semiconductor transition in germanium. Phys. Rev. B 49, 14251-14269 (1994). https://doi.org/10.1103/PhysRevB.49.14251

35. P. Hohenberg, W. Kohn, Inhomogeneous electron gas. Phys. Rev. 136, B864-B871 (1964). https://doi.org/10.1103/PhysR ev.136.B864

36. W. Kohn, L.J. Sham, Self-consistent equations including exchange and correlation effects. Phys. Rev. 140, A1133A1138 (1965). https://doi.org/10.1103/PhysRev.140.A1133

37. J.P. Perdew, K. Burke, M. Ernzerhof, Generalized gradient approximation made simple. Phys. Rev. Lett. 77, 3865-3868 (1998). https://doi.org/10.1103/PhysRevLett.77.3865

38. A.I. Liechtenstein, V.V. Anisimov, J. Zaanen, Densityfunctional theory and strong interactions: orbital ordering in mott-hubbard insulators. Phys. Rev. B 52, R5467-R5470 (1995). https://doi.org/10.1103/PhysRevB.52.R5467

39. S.L. Dudarev, A.I. Liechtenstein, M.R. Castell, G. Briggs, A.P. Sutton, Surface states on $\mathrm{NiO}(100)$ and the origin of the contrast reversal in atomically resolved scanning tunneling microscope images. Phys. Rev. B 56, 4900 (1997). https:// doi.org/10.1103/PhysRevB.56.4900

40. A. Jain, G. Hautier, C.J. Moore, S. Ping Ong, C.C. Fischer et al., A high-throughput infrastructure for density functional theory calculations. Comput. Mater. Sci. 50, 2295-2310 (2011). https://doi.org/10.1016/j.commatsci.2011.02.023

41. S. Grimme, J. Antony, S. Ehrlich, H. Krieg, A consistent and accurate $\mathrm{ab}$ initio parametrization of density functional dispersion correction (DFT-D) for the 94 elements H-Pu. J. Chem. Phys. 132, 154104 (2010). https://doi.org/10.1063/1.3382344

42. H.J. Monkhorst, J.D. Pack, Special points for brillouin-zone integrations. Phys. Rev. B 13, 5188-5192 (1976). https://doi. org/10.1103/PhysRevB.13.5188

43. K. Momma, F. Izumi, Vesta: a three-dimensional visualization system for electronic and structural analysis. J. Appl. Crystallogr. 41, 653-658 (2008). https://doi.org/10.1107/S002188980 8012016

44. S.H. Kim, J.M. Kim, D.B. Ahn, S.Y. Lee, Cellulose nanofiber/ carbon nanotube-based bicontinuous ion/electron conduction networks for high-performance aqueous $\mathrm{Zn}$-ion batteries. Small 16, 2002837 (2020). https://doi.org/10.1002/smll.202002837

45. C. Hu, L. Miao, Q. Yang, X. Yu, L. Song et al., Self-assembly of CNTs on Ni foam for enhanced performance of $\mathrm{NiCoO}_{2} @$ CNT@NF supercapacitor electrode. Chem. Eng. J. 410, 128317 (2020). https://doi.org/10.1016/j.cej.2020.128317

46. L. Kang, M. Zhang, J. Zhang, S. Liu, N. Zhang et al., Dualdefect surface engineering of bimetallic sulfide nanotubes towards flexible asymmetric solid-state supercapacitors. J.
Mater. Chem. A 8, 24053-24064 (2020). https://doi.org/10. 1039/D0TA08979F

47. C. Wang, Z. Song, H. Wan, X. Chen, Q. Tan et al., Ni-Co selenide nanowires supported on conductive wearable textile as cathode for flexible battery-supercapacitor hybrid devices. Chem. Eng. J. 400, 125955 (2020). https://doi.org/10.1016/j. cej.2020.125955

48. X. Zhang, F. Yang, H. Chen, K. Wang, J. Chen et al., In situ growth of $2 \mathrm{D}$ ultrathin $\mathrm{NiCo}_{2} \mathrm{O}_{4}$ nanosheet arrays on $\mathrm{Ni}$ foam for high performance and flexible solid-state supercapacitors. Small 16, 2004188 (2020). https://doi.org/10.1002/smll.20200 4188

49. Q. Tan, X. Li, B. Zhang, X. Chen, Y. Tian et al., Valence engineering via in situ carbon reduction on octahedron sites $\mathrm{Mn}_{3} \mathrm{O}_{4}$ for ultra-long cycle life aqueous $\mathrm{Zn}$-ion battery. Adv. Energy Mater. 10, 2001050 (2020). https://doi.org/10.1002/aenm. 202001050

50. R.F.W. Bader, Atoms in Molecules: A Quantum Theory (Oxford University Press, Oxford, 1990)

51. X. Zhao, H. Wan, P. Liang, N. Wang, C. Wang et al., Favorable anion adsorption/desorption of high rate $\mathrm{NiSe}_{2}$ nanosheets/ hollow mesoporous carbon for battery-supercapacitor hybrid devices. Nano Res. 66, 1-10 (2020). https://doi.org/10.1007/ s12274-020-3257-z

52. Y. Gan, C. Wang, X. Chen, P. Liang, H. Wang, High conductivity $\mathrm{Ni}_{12} \mathrm{P}_{5}$ nanowires as high-rate electrode material for battery-supercapacitor hybrid devices. Chem. Eng. J. 392, 123661 (2019). https://doi.org/10.1016/j.cej.2019.123661

53. M. Gong, Y. Li, H. Zhang, B. Zhang, W. Zhou et al., Ultrafast high-capacity NiZn battery with NiAlCo-layered double hydroxide. Energy Environ. Sci. 7, 2025-2032 (2014). https:// doi.org/10.1039/C4EE00317A

54. Y. Zeng, Z. Lin, Y. Meng, Y. Wang, M. Yu et al., Flexible ultrafast aqueous rechargeable $\mathrm{Ni} / / \mathrm{Bi}$ battery based on highly durable single-crystalline bismuth nanostructured anode. Adv. Mater. 28, 9188-9195 (2016). https://doi.org/10.1002/adma. 201603304

55. J. Liu, M. Chen, L. Zhang, J. Jiang, J. Yan et al., A flexible alkaline rechargeable $\mathrm{Ni} / \mathrm{Fe}$ battery based on graphene foam/ carbon nanotubes hybrid film. Nano Lett. 14, 7180-7187 (2014). https://doi.org/10.1021/nl503852m

56. H. Pan, Y. Shao, P. Yan, Y. Cheng, K.S. Han et al., Reversible aqueous zinc/manganese oxide energy storage from conversion reactions. Nat. Energy 1, 1-7 (2016). https://doi.org/10. 1038/nenergy.2016.39

57. S. Liu, H. Zhu, B. Zhang, G. Li, H. Zhu et al., Tuning the kinetics of zinc-ion insertion/extraction in $\mathrm{V}_{2} \mathrm{O}_{5}$ by in situ polyaniline intercalation enables improved aqueous zinc-ion storage performance. Adv. Mater. 32, 2001113 (2020). https:// doi.org/10.1002/adma.202001113

58. X. Jiang, Z. Li, G. Lu, N. Hu, G. Ji et al., Pores enriched $\mathrm{CoNiO}_{2}$ nanosheets on graphene hollow fibers for high performance supercapacitor-battery hybrid energy storage. Electrochim. Acta 358, 136857 (2020). https://doi.org/10.1016/j. electacta.2020.136857 